\title{
Different Gene Expression and Activity Pattern of Antioxidant Enzymes in Bladder Cancer
}

\author{
EDYTA WIECZOREK ${ }^{1}$, ZBIGNIEW JABLONOWSKI ${ }^{2}$, BARTLOMIEJ TOMASIK ${ }^{3}$, \\ JOLANTA GROMADZINSKA ${ }^{4}$, EWA JABLONSKA ${ }^{1}$, TOMASZ KONECKI ${ }^{2}$, WOJCIECH FENDLER ${ }^{3}$, \\ MAREK SOSNOWSKI ${ }^{2}$, WOJCIECH WASOWICZ ${ }^{4}$ and EDYTA RESZKA ${ }^{1}$ \\ Departments of ${ }^{1}$ Toxicology and Carcinogenesis, and ${ }^{4}$ Biological and Environmental Monitoring, \\ Nofer Institute of Occupational Medicine, Lodz, Poland; \\ ${ }^{2}$ First Department of Urology and ${ }^{3}$ Department of Biostatistics and Translational Medicine, \\ Medical University of Lodz, Lodz, Poland
}

\begin{abstract}
The aim of this study was to evaluate the possible role in and contribution of antioxidant enzymes to bladder cancer (BC) etiology and recurrence after transurethral resection (TUR). We enrolled 40 patients with $B C$ who underwent TUR and 100 sex- and age-matched healthy controls. The analysis was performed at diagnosis and recurrence, taking into account the time of recurrence. Gene expression of catalase (CAT), glutathione peroxidase 1 (GPX1) and manganese superoxide dismutase (SOD2) was determined in peripheral blood leukocytes. The activity of glutathione peroxidase 3 (GPX3) was examined in plasma, and GPX1 and copper-zinc containing superoxide dismutase 1 (SOD1) in erythrocytes. SOD2 and GPX1 expression and GPXI and SODI activity were significantly higher in patients at diagnosis of $B C$ in comparison to controls. In patients who had recurrence earlier than 1 year from TUR, CAT and SOD2 expression was lower (at diagnosis $p=0.024$ and $p=0.434$, at recurrence $p=0.022$ and $p=0.010$ ), while the GPX1 and GPX3 activity was higher (at diagnosis $p=0.242$ and $p=0.394$, at recurrence $p=0.019$ and $p=0.025$ ) compared to patients with recurrence after 1 year from TUR. This study revealed that the gene expression and activity of the antioxidant enzymes are elevated in blood of patients with $B C$, although a low expression of CAT might contribute to the recurrence of $B C$, in early prognosis.
\end{abstract}

Bladder cancer $(\mathrm{BC})$ is the most frequent malignancy of the

Correspondence to: E. Wieczorek, Nofer Institute of Occupational Medicine in Łódź, ul. Św. Teresy od Dzieciątka Jezus 8, 91-348 Łódź, Poland. Tel: +48 426314611, Fax: +48 426568331, e-mail: edytaw@imp.lodz.pl

Key Words: Urinary bladder, bladder cancer recurrence, gene expression, activity, antioxidant enzymes, CAT. urinary system in males (1). The highest incidence rates worldwide have been reported in Europe, with highest male mortality rates in Spain and Poland (2). BC is characterized by frequent recurrence (3). There are two major types of $\mathrm{BC}$ which usually arise from urothelium: non-muscle-invasive BC (NMIBC) and muscle-invasive BC (MIBC). MIBC is usually of a higher tumor stage and grading, with poorer prognosis than NMIBC. Recurrence of NMIBC has been found as rapidly as in a few weeks after treatment/surgery (4). The most commonly applied therapy is transurethral resection (TUR) or partial cystectomy. Generally, in management of MIBC, adjuvant treatment is recommended. Unfortunately, the surgical management of $\mathrm{BC}$ is complicated by the development of recurrence (5). The recurrence of $\mathrm{BC}$ has a crucial effect on survival time because recurrent $\mathrm{BC}$ is more aggressive in its growth pattern than the original lesion. In recent years, great efforts have been made to elucidate the factors contributing to recurrence preventing it after treatment $(6,7)$. In 2013, the criteria of the European Association of Urology (EAU) guidelines for individual patients defined tumors with low, intermediate, and high risk of both recurrence and progression. Thus the European Organization for Research and Treatment of Cancer (EORTC) scoring system and risk tables are commonly used for BC estimation (8).

Formation of free radicals and reactive oxygen species (ROS) can lead to changes in the redox state of cells and may further contribute to oxidative stress (OS). ROS, by regulating gene expression and enzyme activation, serve a role as signaling molecules which regulate genes important in tumor pathogenesis (9). Moreover, generation of ROS through OS can potentially induce cancer $(10,11)$.

Manganese superoxide dismutase (SOD2), copper-zinc containing superoxide dismutase (SOD1), catalase (CAT), and glutathione peroxidase 1 (GPX1) are most important in endogenous antioxidant-scavenging. The enzymatic protection 
of cells from oxidative injury is present in the mitochondrial matrix as SOD2 and cytosolic SOD1 and GPX1. The first step of the antioxidant defense system is SOD2, which converts ROS to hydrogen peroxide $\left(\mathrm{H}_{2} \mathrm{O}_{2}\right)$, which GPX1 and CAT reduce $\mathrm{H}_{2} \mathrm{O}_{2}$ into water and oxygen. Glutathione peroxidase 3 (GPX3) is plasma selenoprotein involved in the metabolism of $\mathrm{H}_{2} \mathrm{O}_{2}$, fatty acid hydroperoxides and phospholipid hydroperoxides. It is, therefore, understandable that different antioxidant enzymes contribute to a number of disease processes, including cancer, neurodegeneration, and cardiovascular and kidney diseases (11). The role of endogenous antioxidant enzymes such as GPX1, GPX3, SOD1, SOD2 and CAT as potential markers of tumor progression and metastasis was shown in recent studies (12-15).

Considering the scavenging role of CAT, GPX1 and SOD2 in the antioxidant pathway, we hypothesized that the gene expression of these enzymes in peripheral blood leukocytes (PBLs) as a 'surrogate' tissue might be related to $\mathrm{BC}$ invasiveness and recurrence. We also speculated that the genes encoding CAT, GPXI and SOD2 may also influence their activity. Moreover, as far as we are aware, the role of gene expression of these important players has not been examined in PBLs of patients with recurrent BC.

\section{Patients and Methods}

Study design. Patients with BC, both female and male $(\mathrm{n}=40)$, treated at the first Department of Urology, Medical University, Lodz, Poland, were recruited and blood specimens were collected between 2005-2011, at two time points: at diagnosis and at recurrence. The median interval from time of diagnosis to recurrence was 12 months (range $=2-48$ months). Therefore patients with first recurrence were stratified into two groups: those with recurrence earlier than 1 year after TUR $(n=20)$ and those with recurrence after 1 year or more from TUR ( $\mathrm{n}=20)$ (Figure 1). All BC were diagnosed histologically according to 1973 World Health Organization criteria as low (G1), intermediate (G2) and high (G3) grade using specimens obtained before TUR $(8,16)$. Tumor stage $(\mathrm{T})$ was evaluated according to the tumor-node-metastasis (TNM) classification (17).

Age-matched healthy controls $(n=100)$ were recruited between 2011-2012, from the Nofer Institute of Occupational Medicine (NIOM), Lodz, Poland. The study was approved by the Ethics Committee of the NIOM (approval number 1/2011). Written informed consent was obtained from all participants of the study.

For the smoking-stratified analyses, patients and controls were divided into two subgroups as those who currently smoked (smokers) and those who did not and had not smoked within the previous 5 years (non-smokers).

Blood sampling. Blood samples were collected into EDTAcontaining tubes. Cells were lysed in RLT lysis buffer with $0.1 \% \beta$ mercaptoethanol. Leukocyte lysate samples were preserved in sterile microtubes immediately after delivery to the laboratory and maintained at $-70^{\circ} \mathrm{C}$ until RNA isolation. Whole blood samples were collected into heparinized tubes. This material was further fractionated by centrifugation into plasma and erythrocytes and stored at $-20^{\circ} \mathrm{C}$, until biochemical analyses.

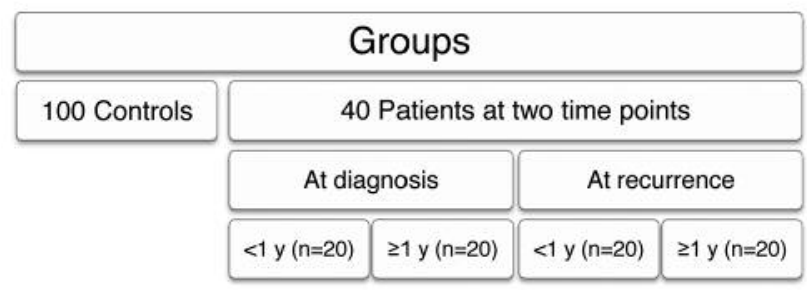

Figure 1. Study design.

Total RNA isolation and cDNA synthesis. Total RNA was isolated using the RNeasy Mini Kit (Qiagen, Hilden, Germany) according to the manufacturer's instructions. Total RNA was eluted in $30 \mu 1$ RNase-free water and stored at $-70^{\circ} \mathrm{C}$ until use. cDNA was synthesized from $250 \mathrm{ng}$ of total RNA, using QuantiTect cDNA synthesis kit (Qiagen) according to the instructions of the manufacturer. The cDNA was stored at $-20^{\circ} \mathrm{C}$ for further gene expression analysis.

mRNA expression of antioxidant enzymes (GPX1, CAT, and SOD2). Gene expression analyses were performed using PBLs of all controls and patients with BC. Synthesized oligonucleotide primers were used in the assay (Metabion International AG, Martinsried, Germany). The mRNA expression levels of target genes were normalized to that of the endogenous control gene glyceraldehyde3-phosphate dehydrogenase $(G A P D H)$. The nucleotide sequences of primers used were as follows: GPX1, 5'-CAA CCA GTT TGG GCA TCA G-3' (forward) and 5'-GTT CAC CTC GCA CTT CTC G-3' (reverse); SOD2, 5'-AAG TAC CAG GAG GCG TTG G-3' (forward) and 5'-TGA ACT TCA GTG CAG GCT GA-3' (reverse); CAT, 5'-CCA TCG CAG TTC GGT TCT-3' (forward) and 5'- GGG TCC CGA ACT GTG TCA-3' (reverse); GAPDH, 5'-AGC CAC ATC GCT CAG ACA C-3' (forward) and 5'-GCC CAA TAC GAC CAA ATC C-3' (reverse). cDNAs were mixed with primers and 2xFastStart SYBR Green Master (Roche Applied Science, Mannheim, Germany). The final volume of the reaction was $10 \mu 1$. The conditions for the amplification reactions were $95^{\circ} \mathrm{C}$ for $15 \mathrm{~s}$, annealing at $60^{\circ} \mathrm{C}$ for $45 \mathrm{~s}$ and extension at $72^{\circ} \mathrm{C}$ for $45 \mathrm{~s}$ (LightCycler 96; Roche Diagnostics, Mannheim, Germany). Each reaction was run in duplicate. The mean normalized expression (MNE) was calculated using the software package Q-Gene (18).

Activity of antioxidant enzymes (GPX1, SOD1, and GPX3). Measurement of GPX1 and SOD1 activity was conducted in erythrocytes, while GPX3 activity was determined in plasma. The activity of GPX1 and GPX3 were measured spectrophotometrically by a method published by Paglia and Valentine (19) using $t$-butyl hydroperoxide as a substrate. The decrease in absorbance at $340 \mathrm{~nm}$ is proportional to the activity of GPX. The activity of SOD1 was quantified by measuring its ability to inhibit the reduction of nitroblue tetrazolium using the method of Beauchamp and Fridovich (20). The oxidation product was determined spectrophotometrically at $540 \mathrm{~nm}$. All absorption spectra were read using a spectrophotometer (Unicam UV4 UV/Vis, Cambridge, UK).

Statistics. Nominal variables are given as numbers with corresponding percentage, whereas continuous variables are presented as means with standard deviation. A $\log 2$ transformation was applied to normalize 
Table I. Demographic, and clinical and pathological characteristics of groups.

\begin{tabular}{lccc}
\hline Characteristic & $\begin{array}{c}\text { Controls, } \\
\mathrm{n}(\%)\end{array}$ & $\begin{array}{c}\text { Patients with BC, } \\
\mathrm{n}(\%)^{\ddagger}\end{array}$ & $p$-Value \\
\hline Age mean \pm SD (years) & $68.7 \pm 8.1$ & $66.2 \pm 9.0$ & $0.151^{\mathrm{b}}$ \\
BMI mean \pm SD $\left(\mathrm{kg} / \mathrm{m}^{2}\right)$ & $27.7 \pm 3.7$ & $25.6 \pm 3.0$ & $0.001^{\mathrm{b}}$ \\
Gender & & & \\
$\quad$ Female & $19(19.0)$ & $9(22.5)$ & $0.815^{\mathrm{a}}$ \\
$\quad$ Male & $81(81.0)$ & $31(77.5)$ & \\
Smoking status* & & & \\
Non-smoker & $79(79.0)$ & $9(23.7)$ & $<0.001^{\mathrm{a}}$ \\
Smoker & $21(21.0)$ & $29(76.3)$ & \\
Tumor stage & & & \\
T1 & $\mathrm{n} / \mathrm{a}$ & $30(75.0)$ & \\
T2 & $\mathrm{n} / \mathrm{a}$ & $5(12.5)$ & \\
T3 & $\mathrm{n} / \mathrm{a}$ & $4(10.0)$ & \\
unknown & $\mathrm{n} / \mathrm{a}$ & $1(2.5)$ & \\
Tumor grade & & & \\
G1 & $\mathrm{n} / \mathrm{a}$ & $20(50.0)$ & \\
G2 & $\mathrm{n} / \mathrm{a}$ & $13(32.5)$ & \\
G3 & $\mathrm{n} / \mathrm{a}$ & $7(17.5)$ & \\
\hline
\end{tabular}

BC: Bladder cancer; BMI: body mass index; n/a: not applicable. ${ }^{\ddagger}$ At diagnosis, *Two patients with $\mathrm{BC}$ had unknown smoking status; ${ }^{\mathrm{a}} \mathrm{chi}-$ square test; ${ }^{b}$-test.

the distribution of MNE. Chi-square tests, with appropriate corrections, were used to test associations between categorical variables. For pairwise comparisons of continuous variables, Student's $t$-test was used. For multi-group comparisons, one-way analysis of variance (ANOVA) was used. Post-hoc comparisons were performed with Tukey's test. $p$-Values lower $<0.05$ were considered as being statistically significant. Statistical analyses were carried out in Statistica 12.5 software (StatSoft, Tulsa, OK, USA) and GraphPad Prism 7 (GraphPad Software, Inc, San Diego, CA, USA).

\section{Results}

Group characteristics. No statistically significant differences were noted for sex $(p=0.815)$ and age $(p=0.151)$ between controls and patients at diagnosis. The control group was more frequently shown to be obese $(p=0.001)$ and reported smoking less frequently $(p<0.001)$ compared to patients with BC (Table I).

Higher gene expression of GPXI in patients with $B C . \mathrm{We}$ examined differences in gene expression of $C A T, G P X 1$, SOD2 between controls and patients at two time points (at diagnosis and recurrence) (Figure 2). Comparison of the three groups demonstrated a significant difference between controls and patients at two time points in GPX1 gene expression $(p=0.014)$. Post-hoc analysis demonstrated that gene expression of GPX1 was significantly higher in patients at diagnosis compared to controls $(p=0.029)$. Moreover, $G P X 1$ gene expression was higher in patients at recurrence

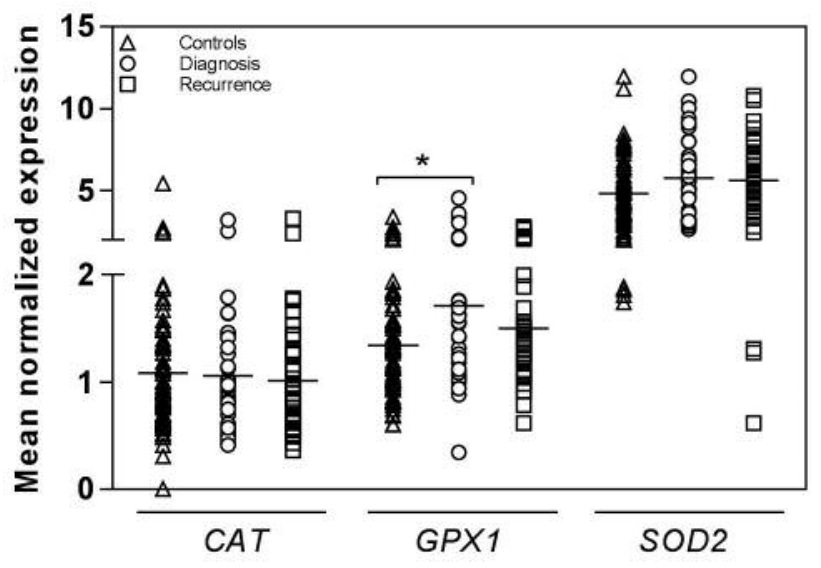

Figure 2. Relative mRNA expression levels of catalase (CAT), glutathione peroxidase 1 (GPX1) and manganese superoxide dismutase (SOD2) in controls and patients with bladder cancer at diagnosis and recurrence. ${ }^{*} p<0.05$ Post-hoc test. Horizontal lines represent mean values.

compared to controls $(p=0.097)$, but the difference was not significant. Comparison of the three groups demonstrated that gene expression of SOD2 was non-significantly increased in patients at diagnosis compared to control $(p=0.067)$. Gene expression of $C A T$ was at the same levels $(p=0.782)$.

The analysis shows that smoking status did not affect the differences in gene expression of $C A T, G P X 1, S O D 2$ in $\mathrm{BC}$ patients at diagnosis $(p=0.501, p=0.059$, and $p=0.979$, respectively).

Gene expression of CAT, GPX1 and SOD2 and tumor characteristics. The gene expression of CAT, GPX1 and SOD2 was compared by tumor characteristics such as tumor stage and tumor grade in patients at diagnosis of $\mathrm{BC}$. There were no significant differences between gene expression according to tumor stage ( $p=0.692, p=0.222$ and $p=0.352$, respectively). Elevated gene expression of GPXI was observed in poorly differentiated tumors (G2 and G3), but was not significant $(p=0.317)$. CAT and SOD2 gene expressions were not associated with tumor grade ( $p=0.664$ and $p=0.457$ ) (Figure 3).

Lower gene expression of CAT and SOD2 among patients with $B C$ with recurrence at $<1$ year. The analysis as performed at diagnosis and recurrence in patients with $\mathrm{BC}$ in relation to the time of recurrence $(<1$ year and $\geq 1$ year) (Figure 4). We show that gene expression of CAT was significantly higher in patients with recurrence $\geq 1$ year from TUR compared to that at $<1$ year, and this was shown at two time points, both diagnosis and recurrence $(p=0.024$ and $p=0.022$, respectively). The gene expression of GPX1 at both time points did not differ significantly in patients with 


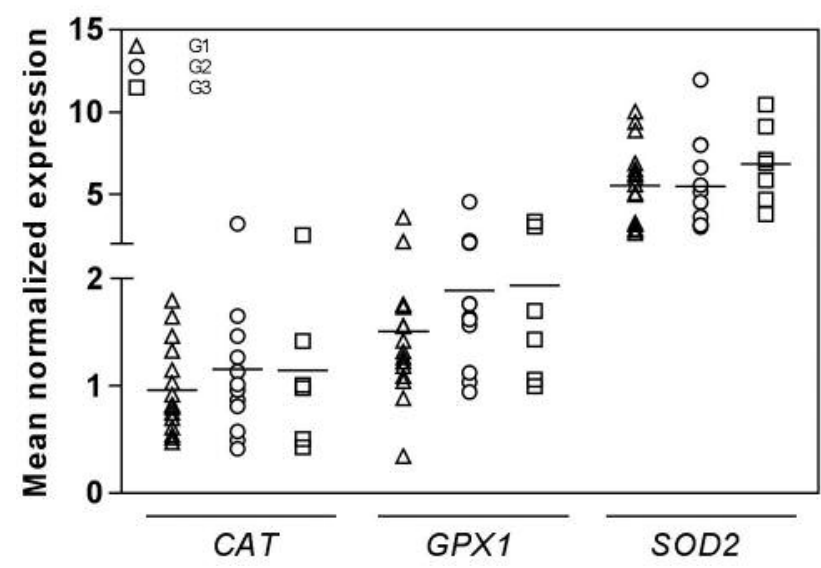

Figure 3. Association between relative mRNA expression of catalase (CAT), glutathione peroxidase 1 (GPX1) and manganese superoxide dismutase (SOD2) and tumor grade at diagnosis. Horizontal lines represent means.

recurrence at $\geq 1$ year compared to those with recurrence at $<1$ year (diagnosis: $p=0.489$; and recurrence: $p=0.786$ ). We observed at diagnosis, SOD2 gene expression did not differ significantly in patients with recurrence at $\geq 1$ year compared to those with recurrence at $<1$ year $(p=0.434$ ) (Figure 4A). At recurrence, however, gene expression of SOD2 was higher in patients with recurrence at $\geq 1$ year compared to those with earlier recurrence $(p=0.010)$ (Figure 4B).

Higher activity of GPXI and SODI in patients with $B C$. Comparison of patients at diagnosis and recurrence with controls demonstrated an increase of GPX1 $(p<0.001)$ and SOD1 activity $(p<0.001)$ (Figure 5$)$. Activity of GPX1 and SOD1 was significantly higher in patients at diagnosis ( $p=0.021$ and $p=0.021$, respectively), and at recurrence of $\mathrm{BC}(p=0.011$ and $p=0.017$, respectively) compared to controls. Activity of GPX3 in controls was at the same levels as those observed at diagnosis and at recurrence $(p=0.126)$.

Activity of GPX1, SOD1 and GPX3 and tumor characteristics. The correlation between activity and pathological features of the tumors at diagnosis was also examined. Activity of GPX1, SOD1 and GPX3 was not significantly associated with tumor stage $(p=0.381, p=0.797$ and $p=0.340$, respectively), as shown in Table II. Activity of GPX1, SOD1 and GPX3 in T1 tumors was at the same levels as those observed in T2 and T3 tumors. Moreover, activity of GPX1, SOD1 and GPX3 was not associated with tumor grade ( $p=0.174, p=0.367$ and $p=0.900$, respectively). Activities of GPX1, SOD1 and GPX3 in G1 tumors were at similar levels as those observed in G2 and G3 tumors.
Table II. Association between activity of glutathione peroxidase 1 (GPX1), copper-zinc containing superoxide dismutase 1 (SOD1) and glutathione peroxidase 3 (GPX3) and tumor characteristics.

\begin{tabular}{lccc}
\hline Tumor stage/grade & GPX1 $(\mathrm{U} / \mathrm{gHb})$ & SOD1 $(\mathrm{U} / \mathrm{mgHb})$ & $\mathrm{GPX} 3(\mathrm{U} / \mathrm{ml})$ \\
\hline T1 & $21.91 \pm 5.55$ & $7.72 \pm 1.97$ & $0.16 \pm 0.03$ \\
T2 & $17.85 \pm 6.80$ & $7.30 \pm 2.63$ & $0.18 \pm 0.02$ \\
T3 & $21.17 \pm 8.27$ & $7.08 \pm 2.02$ & $0.17 \pm 0.02$ \\
$p$-Value & 0.381 & 0.797 & 0.340 \\
G1 & $22.53 \pm 6.06$ & $7.45 \pm 2.10$ & $0.18 \pm 0.04$ \\
G2 & $18.99 \pm 5.18$ & $7.26 \pm 1.65$ & $0.17 \pm 0.03$ \\
G3 & $23.44 \pm 6.83$ & $8.54 \pm 2.27$ & $0.17 \pm 0.02$ \\
$p$-Value & 0.174 & 0.367 & 0.900 \\
\hline
\end{tabular}

Higher activity of GPXI and GPX3 among patients with BC with recurrence at $\geq 1$ year from TUR. The analysis were performed in patients at diagnosis and recurrence in relation to the time of recurrence (Figure 6). There were no differences in GPX1, SOD1 and GPX3 activity levels at diagnosis according to time of recurrence in patients with $\mathrm{BC}(p=0.242$, $p=0.775$, and $p=0.394$, respectively) (Figure 6A). When evaluated at recurrence, higher activity of GPX1 and GPX3 was observed in patients with recurrence $<1$ year compared to $\geq 1$ year recurrence ( $p=0.019$ and $p=0.025$, respectively). Activity of SOD1 at recurrence was not associated with time to recurrence in patients $(p=0.664)$ (Figure 6B).

\section{Discussion}

ROS play an important role in the pathogenesis disease associated with structural remodeling, including carcinogenesis $(9,21)$. It is generally recognized that antistress defense in the cell is very important in carcinogenesis and in the recurrence of cancer (22). Studies show that activity of CAT, SOD2 and GPX1 prevents formation of ROS and hence prevents oxidative damage of proteins, lipids and DNA damage $(23,24)$. Urine markers for BC progression and surveillance are available and commonly used in clinical settings (25). Non-invasive urine-based tests such as ImmunoCyt, BTA TRAK ${ }^{\circledR}$, UroVision using immunoassay, immunohistochemistry, fluorescent in situ hybridization and PCR techniques, and these diagnostic tests would also help to reduce the number of unnecessary cystoscopies (26-28). The expression patterns of several genes and proteins as markers still need to be determined (29). Having this in mind, the present study aimed to investigate the expression of selected genes involved in defense against oxidative stress (CAT, GPX1, SOD1) and activity of enzymes GPX1, GPX3 and SOD1 which are primary antioxidant enzymes in cells and are usually up-regulated by severe oxidative stress (21, 30 ). The role of mRNA expression of antioxidant enzymes in 

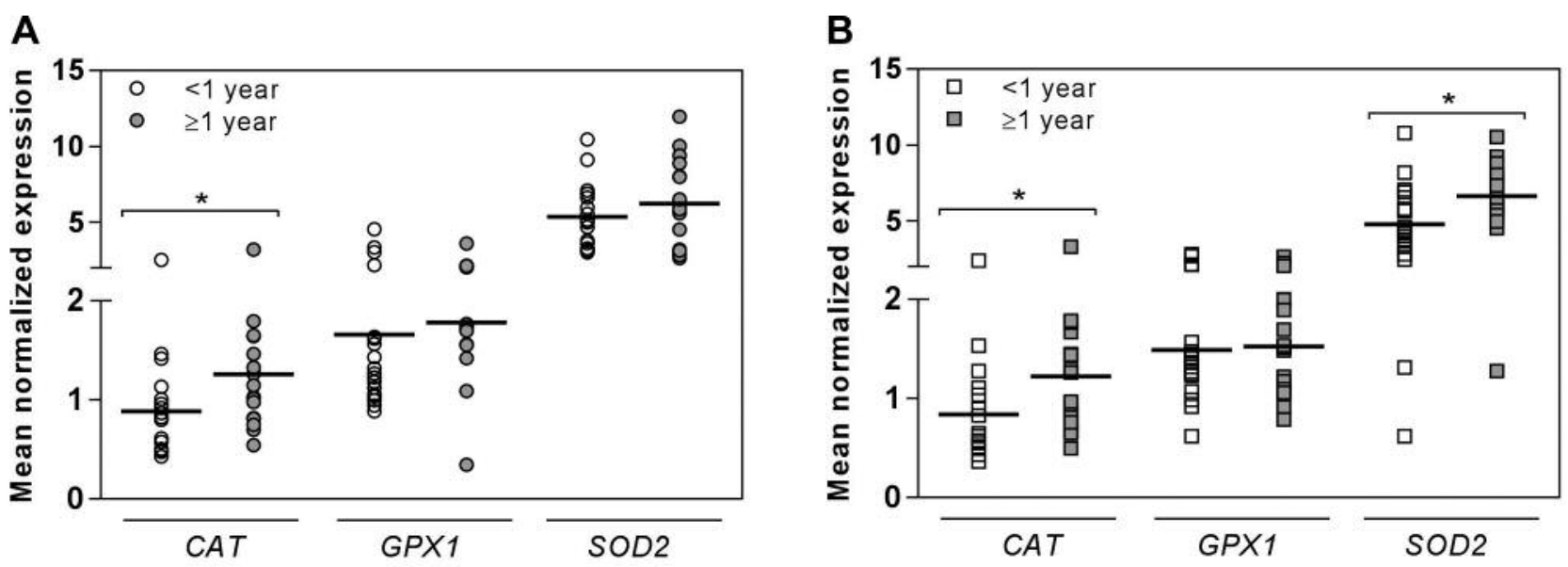

Figure 4. Association between relative mRNA expression of catalase (CAT), glutathione peroxidase 1 (GPX1) and manganese superoxide dismutase (SOD2) and time to recurrence (earlier than 1 year and 1 year or more) in patients at diagnosis (A), and at recurrence (B) of bladder cancer. ${ }^{*} p<0.05$. Horizontal lines represent means.
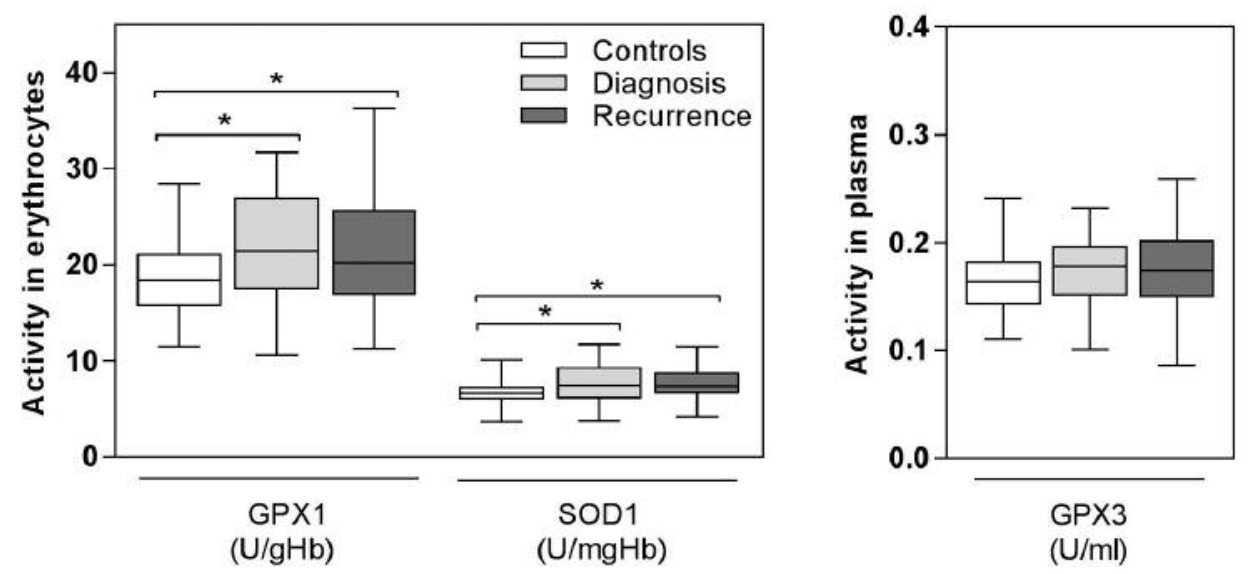

Figure 5. Activity of glutathione peroxidase 1 (GPX1), copper-zinc containing superoxide dismutase 1 (SOD1) and glutathione peroxidase 3 (GPX3) in controls and patients at diagnosis and recurrence of bladder cancer. ${ }^{*} p<0.05$ Post-hoc test. For the box-and-whiskers plots, the whiskers represent the minimum and maximum values, the box boundaries represent the 25th and 75th percentiles, and the line is the median value.

PBLs in oxidative stress associated with invasiveness and recurrence of $\mathrm{BC}$ is unknown. Therefore, the objective of this study was to assess the potential association of activity and gene expression of antioxidant enzymes with invasiveness and recurrence of $\mathrm{BC}$.

Higher gene expression and activity in BC patients at diagnosis. The evidence implicating CAT, GPX1 and SOD2 in the progression of cancer is extensive. Expression of antioxidant enzymes is often up-regulated in patients with $\mathrm{BC}$, because of the protection against cellular and molecular damage caused by ROS. Previous study found alteration of the antioxidant defense system in breast cancer tissue (31).
Alterations caused by tumor in antioxidant enzymes were also observed in our study.

In our study, we noticed the same pattern for antioxidant enzymes in gene expression in PBLs and for activity in the blood. We observed elevated gene expression and activity of antioxidant enzymes in patients with BC patients at both diagnosis and recurrence compared to controls. GPXI and $S O D 2$ genes were overexpressed at diagnosis and recurrence, and there was significantly higher gene expression of GPXI at diagnosis compared to controls. In the same way, the activity of antioxidant enzymes was higher in patients at diagnosis and at recurrence than in controls. This observation is consistent with results from other studies $(32,33)$, which 

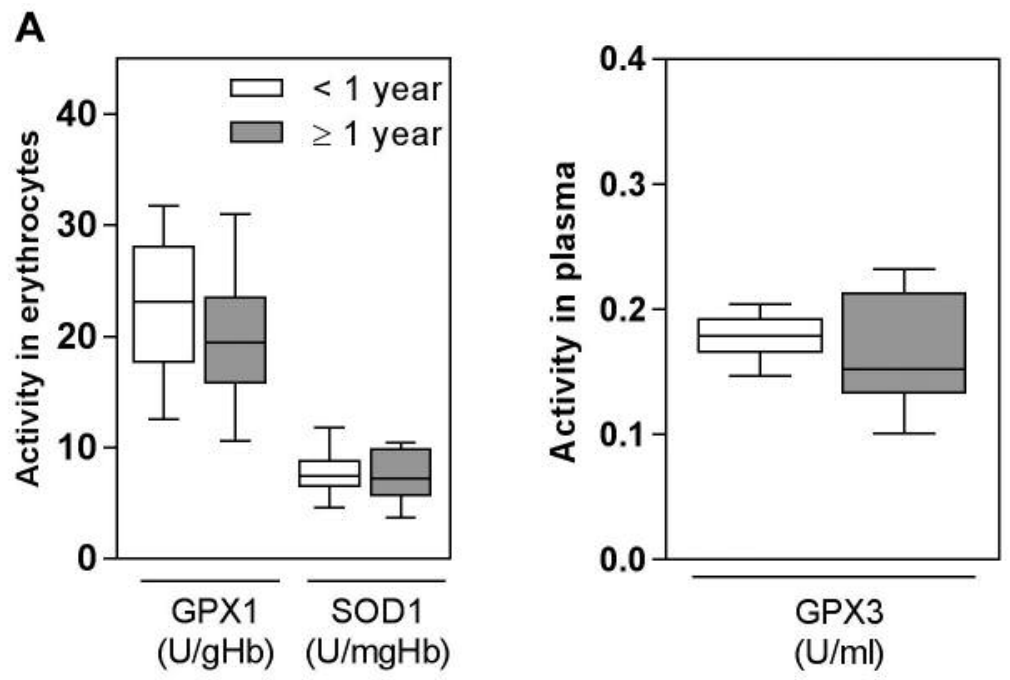

B
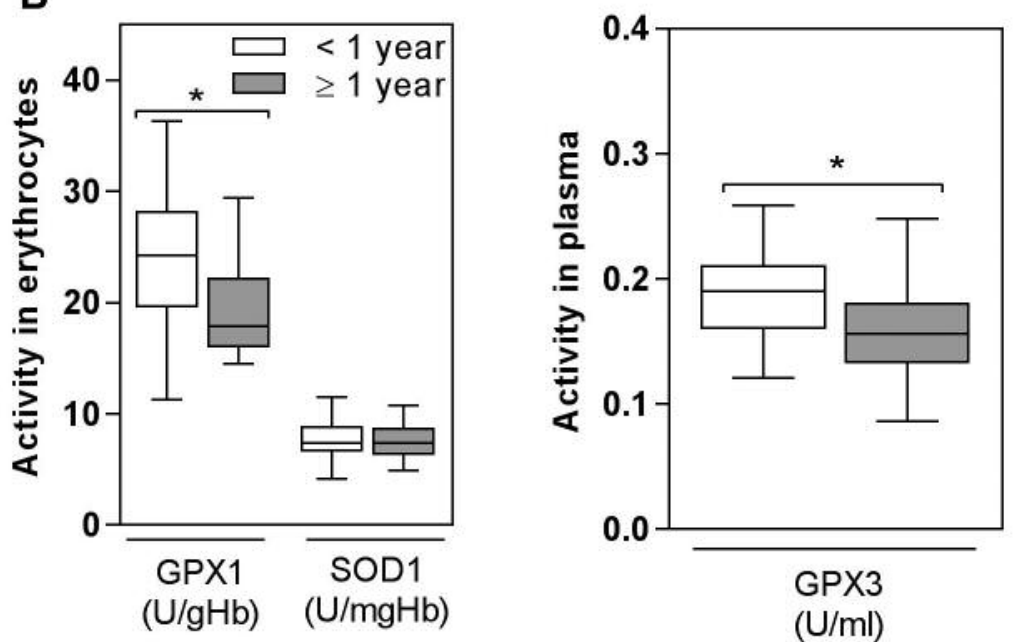

Figure 6. Association between activity of glutathione peroxidase 1 (GPX1), copper-zinc containing superoxide dismutase 1 (SOD1) and glutathione peroxidase 3 (GPX3) and time to recurrence (before 1 year and after 1 year) in patients at diagnosis (A), at recurrence $(B)$ of $B C .{ }^{*} p<0.05 . F o r$ the box-and-whiskers plots, the whiskers represent the minimum and maximum values, the box boundaries represent the 25th and 75 th percentiles, and the line is the median value.

also indicate that SOD and GPX are significantly increased in patients with cancer because they may increase protective effects (14). Some studies have shown, in contrast, that CAT activity was lower in patients with breast cancer $(14,34)$. Previous study confirmed that overexpression of GPX1 alone or in combination with SOD enhanced skin tumor growth in transgenic mice (35). This may suggest the potential impact of the GPX1 and SOD in carcinogenesis. However, we demonstrate that $C A T, G P X 1$ and $S O D 2$ gene expression was not significantly related to tumor characteristics.

Time-to-recurrence associated with different pattern of gene expression and activity of antioxidant enzymes. CAT, GPX1 and SOD2 may prevent carcinogenesis and have a protective effect. Some investigators, in their reports on different cancer types, have concluded that high levels of antioxidant enzymes contribute to cancer progression $(13,36-38)$. Thus, it could be expected that even early recurrence should be associated with high mRNA expression and activity. But our recent report suggests that different patterns of gene expression and activity are associated with time of recurrence.

All our recurrent cases were divided into early- or laterecurrence groups, using 1 year as the cut-off value. This division was applied in patients at two time points: at diagnosis and recurrence. Analysis at diagnosis offers a chance for early prediction of recurrence. Surprisingly, we observed 
changes in gene expression and activity related to time of recurrence. Moreover, the analysis taking into account the time of recurrence showed different patterns of gene expression and activity, with patients with recurrence earlier than 1 year from TUR having higher GPX1 and GPX3 activity compared to patients with recurrence after 1 year. The significantly higher activity of GPX1 and GPX3 was observed at the second time point, recurrence. On the other hand, we observed that gene expression of antioxidant enzymes was lower. CAT and SOD2 gene expression in particular might participate in cancer recurrence. Gene expression of $C A T$ and SOD2 was significantly lower in patients with recurrence at $<1$ year from TUR. Similar results have also been reported in an in vitro model indicating that lower CAT activity plays a role in tumor progression (39). Reiners et al. reported a significant decrease of CAT and SOD activity in mouse skin tumors (40). Nishikawa et al. also showed that retention of CAT activity may inhibit pulmonary metastasis (41). We hypothesized that down-regulation of $C A T$ and SOD2 gene expression is accompanied by increased antioxidative potential expressed as activity of GPX1 and GPX3 enzymes in patients with BC with early recurrence.

Urothelial carcinoma of the bladder as a multifocal disease which, among others, depends on different antioxidant enzymes at different levels such as mRNA expression and enzyme activity. General influence of the antioxidant enzymes on cancer invasiveness and recurrence is difficult to predict. In our opinion, high activity of antioxidant enzymes and low gene expression seems to be associated with a particularly unfavorable outcome (early recurrence) after TUR. The prediction of time to recurrence was probably considerably more accurate when mRNA expression and activity were used in conjunction. Therefore, in order to prevent recurrence, we should pay attention to gene expression as well as enzyme activity. This study examined the transcript levels, which may or may not relate to changes in protein levels due to post-transcriptional regulation. Interestingly, we show that the gene expression and activity of antioxidant enzymes are altered in patients with BC, but they possess different pattern of gene expression and activity in regard to recurrence of $\mathrm{BC}$. According to these results, we can conclude that in particular, gene expression of $C A T$ is important in $\mathrm{BC}$ recurrence and may predict recurrence at any early stage, namely at the time of first diagnosis.

\section{Conflicts of Interest}

The Authors declare they have no conflict of interests related to this work.

\section{Funding}

This work was supported by the NIOM (internal grant no. 1.22/2013 and 1.39/2016) and the Ministry of Science and Higher Education Grant 1978/B/P01/2009/37.

\section{Ethical Approval}

The study was approved by the Ethics Committee of the NIOM. All procedures performed in this study were in accordance with the 1964 Helsinki Declaration and its later amendments.

\section{Informed Consent}

Informed consent was obtained from all individual participants included in the study.

\section{Acknowledgements}

We would like to thank Stefan Markiewicz for his help in preparing the English text of this article.

\section{References}

1 Siegel RL, Miller KD and Jemal A: Cancer Statistics, 2016. CA Cancer J Clin 66: 7-30, 2016.

2 Jemal A, Bray F, Center MM, Ferlay J, Ward E and Forman D: Global cancer statistics. CA Cancer J Clin 61: 69-90, 2011.

3 Gogalic S, Sauer U, Doppler S and Preininger C: Bladder cancer biomarker array to detect aberrant levels of proteins in urine. Analyst 140: 724-735, 2015.

4 Jakse G, Algaba F, Malmstrom PU and Oosterlinck W: A second-look TUR in T1 transitional cell carcinoma: Why? Eur Urol 45: 539-546, 2004.

5 Nargund VH, Tanabalan CK and Kabir MN: Management of non-muscle-invasive (superficial) bladder cancer. Semin Oncol 39: 559-572, 2012.

6 Hermann GG, Mogensen K, Carlsson S, Marcussen N and Duun $\mathrm{S}$ : Fluorescence-guided transurethral resection of bladder tumours reduces bladder tumour recurrence due to less residual tumour tissue in $\mathrm{Ta} / \mathrm{T} 1$ patients: a randomized two-centre study. BJU Int 108: E297-E303, 2011.

7 Bertz S, Otto W, Denzinger S, Wieland WF, Burger M, Stoehr R, Link S, Hofstaedter F and Hartmann A: Combination of CK20 and Ki-67 immunostaining analysis predicts recurrence, progression, and cancer-specific survival in pT1 urothelial bladder cancer. Eur Urol 65: 218-226, 2014.

8 Babjuk M, Burger M, Zigeuner R, Shariat SF, van Rhijn BWG, Comperat E, Sylvester RJ, Kaasinen E, Boehle A, Palou Redorta $\mathrm{J}$ and Roupret $\mathrm{M}$ : EAU guidelines on non-muscle-invasive urothelial carcinoma of the bladder: Update 2013. Eur Urol 64: 639-653, 2013.

9 Havermann S, Buechter C, Koch K and Waetjen W: Role of oxidative stress in the process of carcinogenesis. Studies on Experimental Toxicology and Pharmacology 173-198, 2015.

10 Klaunig JE and Kamendulis LM: The role of oxidative stress in carcinogenesis. Annu Rev Pharmacol Toxicol 44: 239-267, 2004.

11 Pisoschi AM and Pop A: The role of antioxidants in the chemistry of oxidative stress: A review. Eur J Med Chem 97: 5574, 2015.

12 Miar A, Hevia D, Munoz-Cimadevilla H, Astudillo A, Velasco J, Sainz RM and Mayo JC: Manganese superoxide dismutase (SOD2/MnSOD)/catalase and SOD2/GPX1 ratios as biomarkers for tumor progression and metastasis in prostate, colon, and lung cancer. Free Radic Biol Med 85: 45-55, 2015. 
13 Hempel N, Ye H, Abessi B, Mian B and Melendez JA: Altered redox status accompanies progression to metastatic human bladder cancer. Free Radic Biol Med 46: 42-50, 2009.

14 Ray G, Batra S, Shukla NK, Deo S, Raina V, Ashok S and Husain SA: Lipid peroxidation, free radical production and antioxidant status in breast cancer. Breast Cancer Res Treat 59: 163-170, 2000.

15 Sadati Zarrini A, Moslemi D, Parsian H, Vessal M, Mosapour A and Shirkhani Kelagari Z: The status of antioxidants, malondialdehyde and some trace elements in serum of patients with breast cancer. Caspian J Intern Med 7: 31-36, 2016.

16 Otto W, Denzinger S, Fritsche HM, Burger M, Wieland WF, Hofstädter F, Hartmann A and Bertz S: The WHO classification of 1973 is more suitable than the WHO classification of 2004 for predicting survival in pT1 urothelial bladder cancer. BJU Int 107: 404-408, 2011.

17 Sobin LH, Gospodariwicz M, Wittekind C, editors: TNM classification of malignant tumors. UICC International Union Against Cancer 7: 262-265, 2009.

18 Simon P: Q-Gene: processing quantitative real-time RT-PCR data. Bioinformatics 19: 1439-1440, 2003.

19 Paglia DE and Valentin WN: Studies on the quantitative and qualitative characterization of erythrocyte glutathione peroxidase. J Lab Clin Med 70: 158-169, 1967.

20 Beaucham C and Fridovic I: Superoxide dismutase: improved assays and an assay applicable to acrylamide gels. Anal Biochem 44: 276-287, 1971.

21 Brigelius-Flohe R and Maiorino M: Glutathione peroxidases. BBA-Gen Subjects 1830: 3289-3303, 2013.

22 Sun Y: Free radicals, antioxidant enzymes, and carcinogenesis. Free Radic Biol Med 8: 583-599, 1990.

23 Baliga MS, Wang H, Zhuo P, Schwartz JL and Diamond A: Selenium and GPX-1 overexpression protect mammalian cells against UV-induced DNA damage. Biol Trace Elem Res 115: 227-241, 2007.

24 Aruoma OI, Grootveld $\mathrm{M}$ and Bahorun T: Free radicals in biology and medicine: From inflammation to biotechnology. Biofactors 27: 1-3, 2006.

25 Whitson JM, Porten SP, Hussein AA and Meng MV: The efficient and effective use of exfoliative urinary markers. Urology Practice 3: 195-202, 2016.

26 Xylinas E, Kluth LA, Rieken M, Karakiewicz PI, Lotan Y and Shariat SF: Urine markers for detection and surveillance of bladder cancer. Urol Oncol-Semin Or I 32: 222-229, 2014.

27 Konety BR: Molecular markers in bladder cancer: a critical appraisal. Urol Oncol-Semin Or I 24: 326-337, 2006.

28 Parker J and Spiess PE: Current and emerging bladder cancer urinary biomarkers. The Scientific World Journal 11: 1103-1112, 2011.

29 Holyoake A, O’Sullivan P, Pollock R, Best T, Watanabe J, Kajita Y, Matsui Y, Ito M, Nishiyama $\mathrm{H}$ and Kerr N: Development of a multiplex RNA urine test for the detection and stratification of transitional cell carcinoma of the bladder. Clin Cancer Res 14: 742-749, 2008.
30 Fridovich I: The biology of oxygen radicals. Science 201: 875880, 1978.

31 Punnonen K, Ahotupa M, Asaishi K, Hyoty M, Kudo R and Punnonen R: Antioxidant enzyme activities and oxidative stress in human breast cancer. J Cancer Res Clin Oncol 120: 374-377, 1994.

32 Yeh CC, Hou MF, Tsai SM, Lin SK, Hsiao JK, Huang JC, Wang LH, Wu SH, Hou LA, Ma H and Tsai LY: Superoxide anion radical, lipid peroxides and antioxidant status in the blood of patients with breast cancer. Clin Chim Acta 361: 104-111, 2005.

33 Connor KM, Hempel N, Nelson KK, Dabiri G, Gamarra A, Belarmino J, Van De Water L, Mian BM and Melendez JA: Manganese superoxide dismutase enhances the invasive and migratory activity of tumor cells. Cancer Res 67: 10260-10267, 2007.

34 Seraj AK, Shankhar M, Raju KD, Punam J, Anju P and Rajat KA: Antioxidants and lipid peroxidation status in women with breast cancer. International Medical Journal Malaysia 14: 71-75, 2015.

$35 \mathrm{Lu}$ YP, Lou YR, Yen P, Newmark HL, Mirochnitchenko OI, Inouye $M$ and Huang MT: Enhanced skin carcinogenesis in transgenic mice with high expression of glutathione peroxidase or both glutathione peroxidase and superoxide dismutase. Cancer Res 57: 1468-1474, 1997.

36 Connor KM, Hempel N, Nelson KK, Dabiri G, Gamarra A, J Belarmino, Van De Water L, Mian BM and Melendez JA: Manganese superoxide dismutase enhances the invasive and migratory activity of tumor cells. Cancer Res 67: 10260-10267, 2007.

37 Hempel N, Carrico PM and Melendez JA: Manganese superoxide dismutase (Sod2) and redox-control of signaling events that drive metastasis. Anticancer Agents in Med Chem 11: 191-201, 2011.

38 Hempel N, Ye H, Abessi B, Mian B and Melendez JA: Altered redox status accompanies progression to metastatic human bladder cancer. Free Radic Biol Med 46: 42-50, 2009.

39 Gupta A, Butts B, Kwei KA, Dvorakova K, Stratton SP, Briehl MM and Bowden GT: Attenuation of catalase activity in the malignant phenotype plays a functional role in an in vitro model for tumor progression. Cancer Lett 173: 115-125, 2001.

40 Reiners JJ Jr, Kodari E, Cappel RE and Gilbert HF: Assessment of the antioxidant/prooxidant status of murine skin following topical treatment with 12-O-tetradecanoylphorbol-13-acetate and throughout the ontogeny of skin cancer. Part II: Quantitation of glutathione and glutathione disulfide. Carcinogenesis 12: 23452352, 1991.

41 Nishikawa M, Tamada A, Kumai H, Yamashita F and Hashida M: Inhibition of experimental pulmonary metastasis by controlling biodistribution of catalase in mice. Int $\mathrm{J}$ Cancer 99: 474-479, 2002. 